\title{
CORPO ESTRANHO RETIDO NA CAVIDADE ABDOMINAL DURANTE ONZE ANOS
}

\section{RETAINED SURGICAL SPONGE IN THE ABDOMINAL CAVITY FOR ELEVEN YEARS}

\section{Jane Bunahum de Carvalho ${ }^{1}$ José Carlos Vinhaes, TCBC - RJ ${ }^{2}$}

\section{INTRODUÇÃO}

Os corpos estranhos intra-abdominais, resultantes de intervenções cirúrgicas, não têm merecido destaque na literatura médica, devido, provavelmente, a razões legais. Apesar disto, sua incidência continua muito elevada, alcançando 1 por 1.000 a 1.500 laparotomias ${ }^{1}$.

Além de apresentarem alta morbi-mortalidade por complicações como fístulas, obstruções e formação de abscessos, os corpos estranhos são, algumas vezes, de difícil diagnóstico pré-operatório.

Relatamos o caso de um paciente que manteve-se assintomático ao longo de onze anos, apesar de abrigar uma enorme compressa cirúrgica na loja esplênica, cujo diagnóstico foi confirmado, apenas, durante laparotomia exploradora.

\section{RELATO DO CASO}

S.G.C. masculino, 54 anos, branco, motorista particular, admitido na Clínica Médica de nosso hospital em janeiro de 2002, queixando-se de que há dois meses apresentava dor no hipocôndrio esquerdo e anorexia que o impediam de trabalhar. Ao exame físico, encontrava-se hidratado, hipocorado $++/ 4$, acianótico, eupneico, anictérico e apirético. Apresentava cicatriz abdominal, cirúrgica, mediana, do apêndice xifóide até $2 \mathrm{~cm}$ abaixo da cicatriz umbilical. Indagado sobre antecedentes cirúrgicos, relatou que, em setembro de 1991, após acidente automobilístico, no qual fraturara dois arcos costais à esquerda, fora submetido à esplenectomia de urgência por ruptura do baço.
Durante sua internação na clínica médica, realizou, além dos exames laboratoriais, radiografia de tórax e abdome, que revelavam imagem hipotransparente heterogênea tipo "miolo de pão", que rechaçava o estômago e endoscopia digestiva alta que evidenciou grande redução da luz do estômago. A ultra-sonografia do abdome mostrava imagem hiperecogênica, heterogênea na face anterior do apêndice xifóide, além de imagem hiperecogênica com sombra acústica posterior compacta e com periferia hipoecóica, medindo cêrca de 9.43 x $8.53 \mathrm{~cm}$ de diâ-

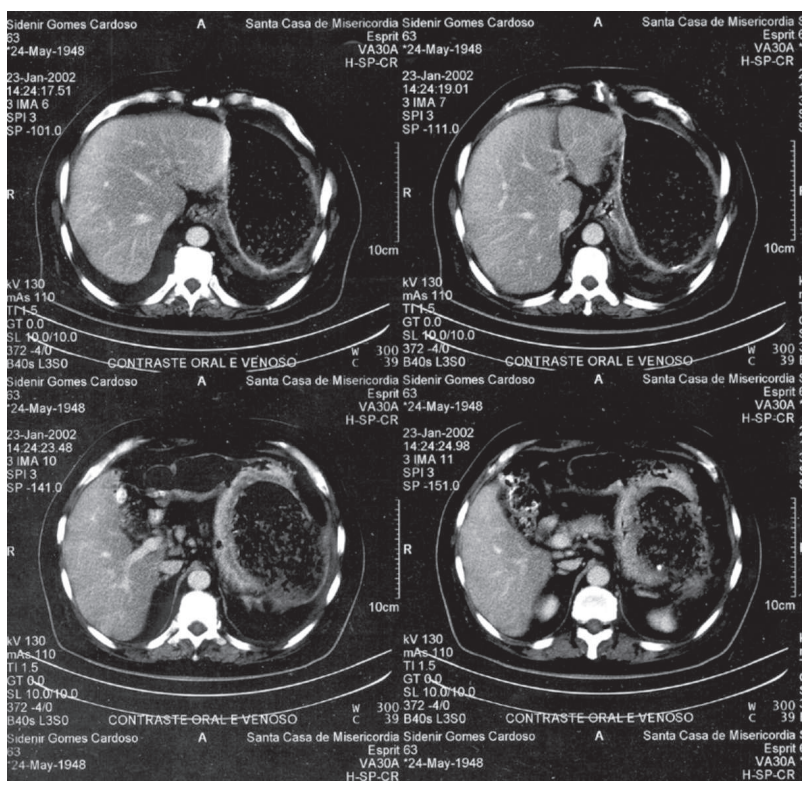

Figura 1 - Tomografia computadorizada, mostrando massa tipo "miolo de pão", deslocando o estômago e com ápice ao nível do apêndice xifóide, local onde se desenvolveu abaulamento comflogose.

1. Médica Clínica da $15^{\mathrm{a}}$ Enf ${ }^{\mathrm{a}}$ do Hospital Geral da Sta. Casa de Misericórdia do Rio de Janeiro.

2. Chefe do Serviço da $15^{\text {a }}$ Enf ${ }^{\text {a }}$ do Hospital Geral da Sta. Casa de Misericórdia do Rio de Janeiro.

Recebido em 03/12/2002

Aceito para publicação em 29/04/2003

Trabalho realizado na $15^{\mathrm{a}}$ Enf $^{\mathrm{a}}$ do Hospital Geral da Sta. Casa de Misericórdia do Rio de Janeiro. 
metro no hipocôndrio esquerdo, com provável contigüidade com a lesão parietal.

A tomografia computadorizada ratificou os achados radiológicos e ultra-sonográficos (Figura 1). $\mathrm{O}$ paciente evoluiu com piora da dor, perda ponderal importante e abaulamento com flogose na região do apêndice xifóide, sugerindo a formação de um empiema de necessidade.

Transferido para o Serviço de Cirurgia Geral, foi realizada pequena incisão infra-xifoidiana, com drenagem de grande quantidade de secreção purulenta, de odor fétido. Imaginando tratar-se de fístula colônica, tentamos realizar duas fistulografias sem êxito, pois não havia progressão do contraste. Após nova tomografia que mantinha imagem indefinida na loja esplênica rechaçando o estômago, e uma linha de continuidade até o apêndice xifóide, que invadia o hipocôndrio direito, decidimos realizar uma laparotomia exploradora, que revelou grande compressa localizada na loja esplênica, tamponada pelo estômago (Figura 2). O corpo estranho foi retirado e a loja esplênica drenada. $\mathrm{O}$ paciente evoluiu satisfatoriamente até receber alta em abril de 2002.

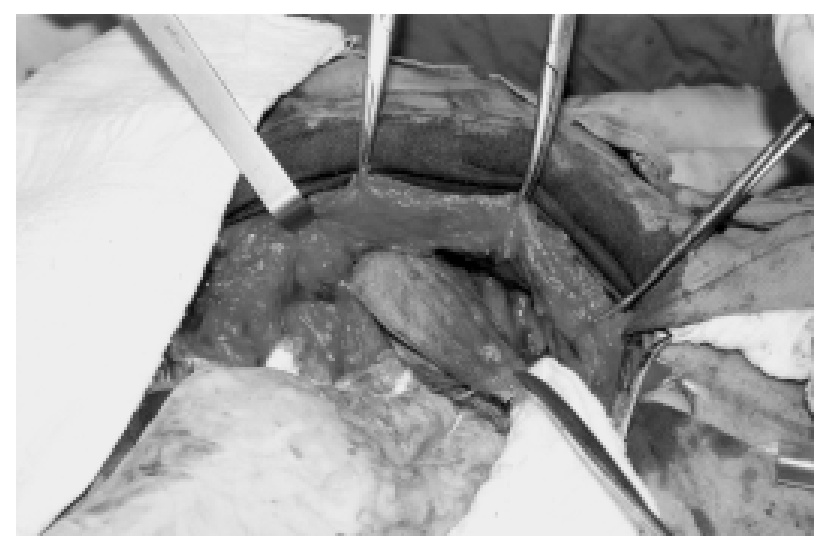

Figura 2 - Aspecto per-operatório, no momento em que era retirada a compressa da loja explênica.

\section{DISCUSSÃO}

Os parcos relatos na literatura norte-americana e européia de corpos estranhos intra-abdominais, devem-se, provavelmente, às implicações legais que resultam em processos e conseqüentes indenizações. Um estudo prospectivo realizado durante dez anos, na Clínica de Cirurgia e Hiper-Alimentacão em Guadalajara no México, acompanhou 24 casos de corpos estranhos após operações abdominais, nos quais todos os pacientes achavam-se sintomáticos ${ }^{2}$. Oito pacientes apresentavam sepse abdominal, quatro obstrução intestinal, quatro fístulas êntero ou cólon-cutâneas, três apresentavam dor abdominal inespecífica, dois massa palpável, granuloma em outros dois e uma paciente evoluiu com descarga vaginal. O diagnóstico só foi estabelecido no pré-operatório, em quinze casos, através de exames de imagem. A taxa de morbidade foi de $50 \%, 18 \%$ precisaram de re-intervenção cirúrgica por causa do surgimento de fístulas e da persistência de sepse e a taxa de mortalidade chegou a $10 \%{ }^{2}$.

Ao apresentarmos este caso queremos chamar a atenção para o fato do paciente abrigar uma grande compressa cirúrgica na cavidade abdominal e manter-se assintomático ao longo de quase onze anos. Os corpos estranhos intra-peritoneais podem apresentar-se clinicamente como um pseudo-tumor, como uma síndrome séptica, como uma síndrome oclusiva ou podem ser encapsulados e permanecerem assintomáticos, dependendo do material de que são constituídos. Freqüentemente, é deflagrado um processo de auto-eliminação ${ }^{3}$. Quando a resposta inflamatória é do tipo exudativa, forma-se um abscesso, como tentativa do organismo para eliminar o corpo estranho. A evolução menos comum é a penetração do material através da parede do intestino, total ou parcialmente, podendo ser eliminado pelo tubo digestivo.

As compressas cirúrgicas são feitas de algodão, material inerte, que não costuma estimular uma reação bioquímica específica. Ocorre, então, uma resposta asséptica, através de uma carapaça de fibrina, que se adere ao material inerte e o encapsula, resultando num granuloma de corpo estranho. O granuloma de corpo estranho é o resultado de uma reação inflamatória crônica, na qual o tipo celular predominante é um macrófago ativado que se transforma em células semelhantes às células epiteliais, cercadas por um colar de leucócitos mononucleares, principalmente linfócitos e plasmócitos. Os granulomas mais velhos desenvolvem uma bainha capsular de fibroblastos e tecido conjuntivo. As células epitelióides se fundem, constituindo células gigantes na periferia, contendo uma grande massa citoplasmática com múltiplos e pequenos núcleos dispostos ao acaso. Estes núcleos distribuídos aleatoriamente podem conter fragmentos de "debris" ingeridos pelos macrófagos 4 .

Ao retirarmos o corpo estranho do abdome do paciente, pudemos perceber que o mesmo encon- 
trava-se em sua forma, textura e tamanho originais, corroborando com a fisiopatologia descrita acima. No entanto, cabe aqui uma pergunta: qual ou quais fatores foram determinantes para a quebra da barreira de proteção do corpo estranho? Não há na história anterior ao início dos sintomas nada que pudesse justificar a mudança no quadro clínico, transformando a resposta inflamatória, tardiamente, em exsudativa. Vale ressaltar que, entre o início dos sintomas e a resolução do caso, em nenhum momento houve sinal de sepse.

\begin{abstract}
A retained foreign body in the abdominal cavity following surgery is a continuing problem. Despite precautions, the incidence is grossly underestimated. Presentation is possible as a pseudotumour, occlusive, or septic syndrome. We describe a case of retained surgical sponge that remained asymptomatic for eleven years.
\end{abstract}

\section{REFERÊNCIAS}

1. Rappaport, W., Haynes, K. The retained surgical sponge following intra-abdominal surgery. Arch Surg 1990; 125: 405-7.

2 Gonzalez-Ojeda A. et al. Retained foreign bodies following intra-abdominal surgery. Hepatogastroenterology 1999 Mar-Apr; 46 (26): 808-12.
3. Cyhan, A. et al. Surgical gauze pseudotumor eroding into the intestine. Gazi medical journal 8:122-125, 1997. Disponível em http://demolar.pleksus.net.tr/gazi-yeni/ journal/1997.

4. Robbins. Patologia estrutural e funcional. $5^{\text {a }}$ ed. Rio de Janeiro: Guanabara Koogan; 1997.

Endereço para correspondência:

Prof. José Carlos Vinhaes

Av. Gilberto Amado, 609 - Barra da Tijuca

CEP: 22620-00 - Rio de Janeiro (RJ) 